\title{
Influences and consequences resulting in addictions in general and to chronic alcoholism, especially for patients with spinal cord injury
}

\author{
STOICA Simona-Isabelle ${ }^{1,2}$, TĂNASE Ioana ${ }^{2}$, ONOSE Gelu ${ }^{1,2}$
}

Editor: Constantin MUNTEANU, E-mail: office@bioclima.ro

Corresponding author: STOICA Simona-Isabelle, E-mail: stoicasimonaisabelle@yahoo.com

1. University of Medicine and Pharmacy "Carol Davila" (UMPCD), in Bucharest, Romania

2 Teaching Emergency Hospital "Bagdasar-Arseni” (TEHBA), Bucharest, Romania

\begin{abstract}
Introduction: Spinal cord injury can be a cause of severe disability, with important consequences at the individual and social levels. Causes are often produced by falls or road accidents; and addictions (particularly chronic ethylism) also increase the risk of vertebral-medullary lesions.

Materials and Methods: With with the approval of the TEHBA Ethics Commission (no.17464/14.06.2019), we used specific tests (DASS-21, MOS SF-36, SMAST, AUDIT, CAGE, AIS) and we questioned a group of patients admitted to the THEBA Neuro-Muscle Recovery Clinic after being treated in the Spinal Neurosurgery Service for acute and subacute vertebral medullary trauma.

Results: We evaluated the link between addictions (especially ethanol), the risk of spinal cord injury, and the underlying subacute evolution of patients with this pathology.

Conclusions: Substance abuse (especially ethanol) increases the risk of spinal cord injury and is a serious public health problem.
\end{abstract}

\section{Keywords: SCI, DASS-21, MOS SF-36, AUDIT, CAGE, SMAST, Neuromuscular Recovery}

\section{INTRODUCTION}

Spinal cord injury can be a cause of severe disability, with important consequences at the individual and social levels (1) (2) (3). Causes are often produced by falls or road accidents (4); and addictions (particularly chronic ethylism) also increase the risk of vertebral-medullary lesions (5) (6). We assessed the severity of the deficit after spinal cord injury using the AIS scale (American Spinal Injury Association (ASIA) Impairment Scale) (7). It is difficult to appreciate the individual consumption of ethanol in the population. That is why psychological tests are used trying to quantify the amount of alcohol consumed daily. Such tests are: AUDIT, CAGE, SMAST.

We evaluated the psychological impact of spinal cord injury using the DASS-21 and MOS SF36 scales, with an important role in assessing patients' emotional changes.

\section{Materials and Methods:}

With with the approval of the TEHBA Ethics Commission (no.17464/14.06.2019), we used specific tests (DASS 21, MOS SF36, SMAST, AUDIT, CAGE, AIS) and we questioned a group of 17 patients admitted to the SCUBA Neuro-Muscle Recovery Clinic after being treated in the Spinal Neurosurgery Service for acute and subacute vertebral medullary trauma.
AUDIT (Alcohol Use Disorders Identification Test) is made for the early identification of behavioral disorders regarding ethanolic consumption using 10 questions. This test measures the consumption of alcohol units (of 10 grams each) and it is considered that a weekly consumption of more than 10 units is harmful. An AUDIT score greater than or equal to 8 indicates a potentially harmful ethanolic consumption (8) (9) (10).

CAGE (consisting of the acronyms Cut, Annoyed, Guilty and Eye-opener) is a quick test that assesses by 4 questions the risk of ethanol abuse. A CAGE score greater than 2 indicates a problem with ethanolic abuse (11) (12) (13).

SMAST (Short Michigan Alcoholism Screening Test) is a questionnaire with 13 questions that assesses the history of ethanol consumption, and a result greater than 4 indicates a potential ethanolic abuse (14) (15).

DASS-21 (Depression Anxiety Stress Scales) is a test used in the posttraumatic clinical evaluation (through 21 questions) of patients. The test provides data on mood, anxiety and stress (16) (17) (18).

MOS SF-36 (Medical Outcomes Study 36-item shortform) is a test consisting of 36 questions that measure general health. The levels evaluated with MOS SF-36 are: "physical functioning," "role physical," "bodily pain," "general health," "vitality," "social functioning," "role emotional," and "mental health", quantifying the patient's physical and mental function (19) (20) (21). 
Statistical processing of patient data was performed using Microsoft Office 2013.

\section{Results}

We evaluated the link between addictions (especially ethanol), the risk of vertebro-medullary trauma, and the underlying subacute evolution of patients with this pathology.

We studied a group of 17 patients consisting of 6 women $(35 \%)$ and $11(65 \%)$ men hospitalized after spinal cord injury in THEBA.

\section{GENDER DISTRIBUTION OF PATIENTS}

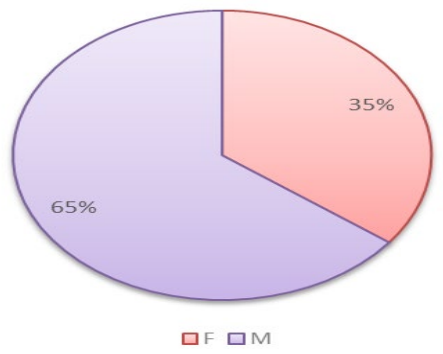

Fig 1. Gender distribution of patients

We evaluated the dependence on ethanol using the AUDIT, CAGE and SMAST tests. We observed a directly proportional relationship between AUDIT, SMAST and CAGE results (F test 0,002, Pearson test 0,746). Only men patients were with addictions: 7 (AUDIT, SMAST) / 4 (CAGE). No woman had any addictions.

CORRELATION AUDIT- SMAST - CAGE

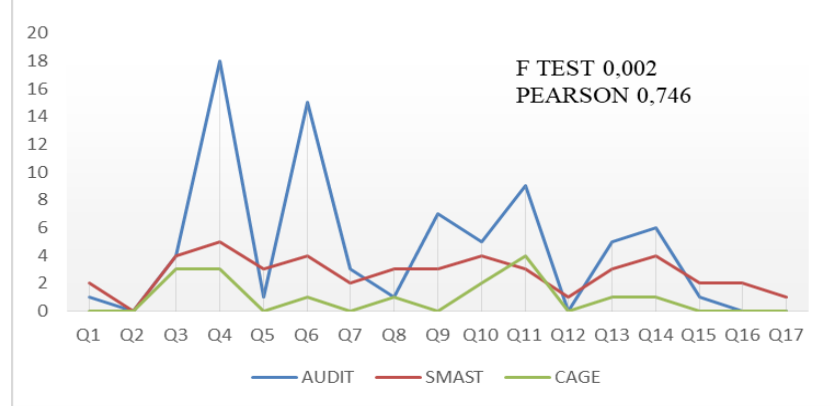

Fig 2. Correlation between AUDIT, SMAST, CAGE

In AIS patient evaluation we found that: of the women, 3 had the score AIS A and 3 the score AIS C; of the men, 4 had AIS A score, 5- AIS C score and 2 AIS D score.

AIS/ FRANKEL RESULTS

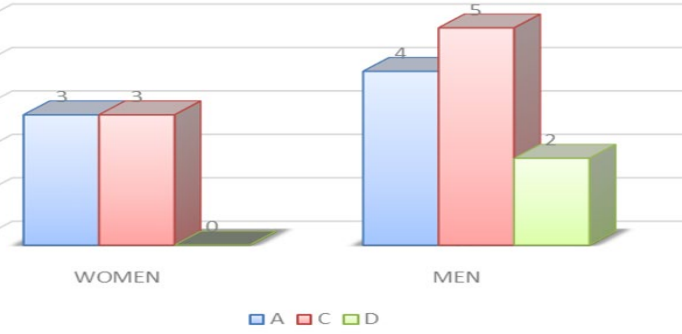

Fig 3. AIS/ Frankel scale results
Knowing that AIS A gradation describes a complete (particularly severe) neurological lesion, unlike grades C or $\mathrm{D}$ (which describe incomplete neurological lesions, with more optimistic recovery prospects); we have comparatively researched the type of neurological deficit (A gradation versus $\mathrm{C}+\mathrm{D}$ gradation) in patients consuming and not consuming alcoholic beverages abusively.

At the AUDIT test, AIS A gradation had 2 ethanolic patients together with 5 non-ethanolic patients; and grade $\mathrm{C}$ and $\mathrm{D}$ had 5 ethanolic patients and 5 non-ethanolic patients.

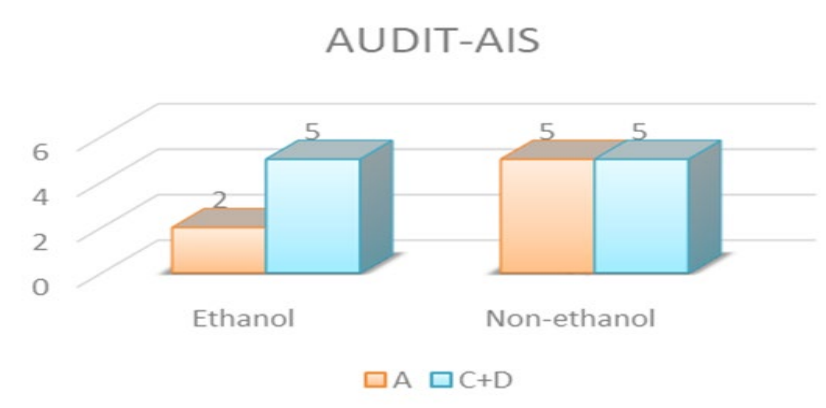

Fig 4. AUDIT- AIS RESULTS

CAGE testing showed that of the ethanolic patients, 1 had AIS A grading and 3 had C and D grading; and of the non-ethanolic patients, 6 had AIS A gradation, and 7 had $\mathrm{C}$ and $\mathrm{D}$ gradations.

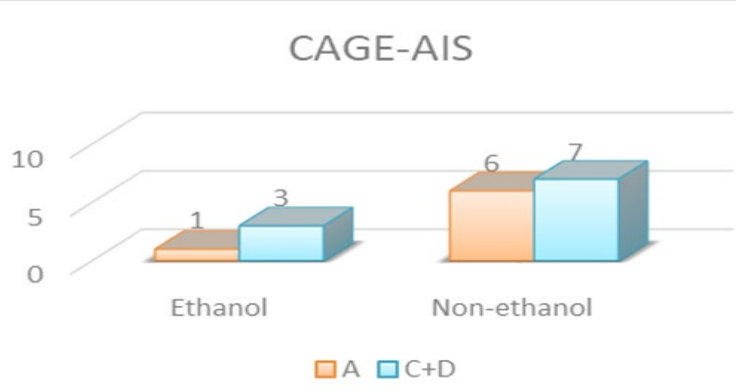

Fig 5. CAGE- AIS results

In the SMAST test, the AIS grades were as follows: A (for one ethanolic patient and 6 non-ethanolic patients), $\mathrm{C}$ and D (for 6 ethanolic patients and for 4 non-ethanolic patients).

\section{SMAST- AIS}

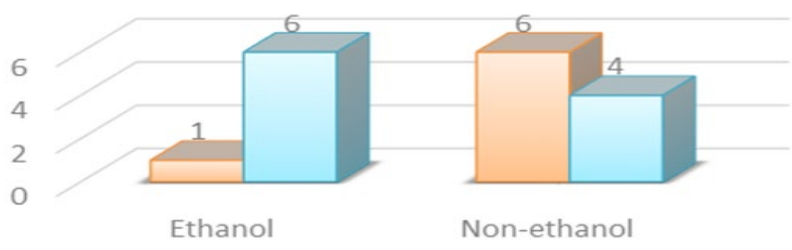

$\square \mathrm{A} \square \mathrm{C}+\mathrm{D}$

Fig 6. SMAST- AIS results 
We appreciated the results of the MOS SF36 test by achieving averages in the population of ethanolconsuming patients, compared to non-ethanol-consuming patients. The results of the M36 SF36 comparative test in non-alcoholic versus alcoholic patients were: 26,5- 20 (for physical functioning), 30-25 (for role in limitation physical health), 53,43-71,43 (for role limitation in emotional problems), 58,5-59,29 (for energy/ fatigue), 71,6-69,14 (for emotional well being), 77,5-67,86 (for social functioning), 46,25- 35,36 (for pain), 72,5-81,43 (for general health), 45-32,14 (for health change).

MOS SF36 IN NON-ALCOHOLIC PATIENTS

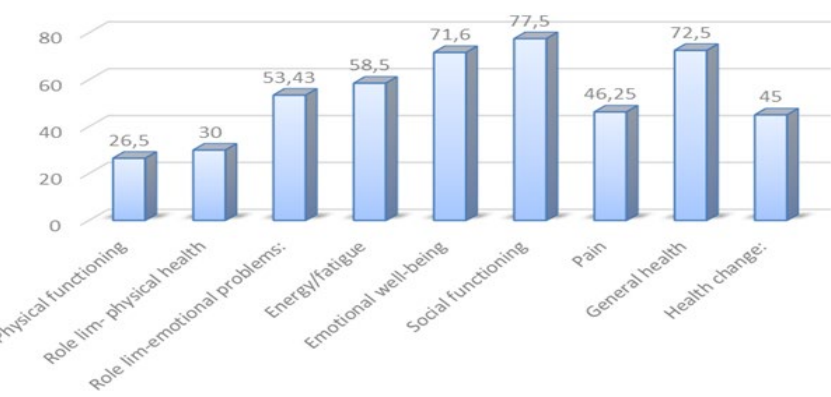

Fig 7. MOS SF-36 results in non-alcoholic patiens MOS SF-36 IN ALCOHOLIC PATIENTS

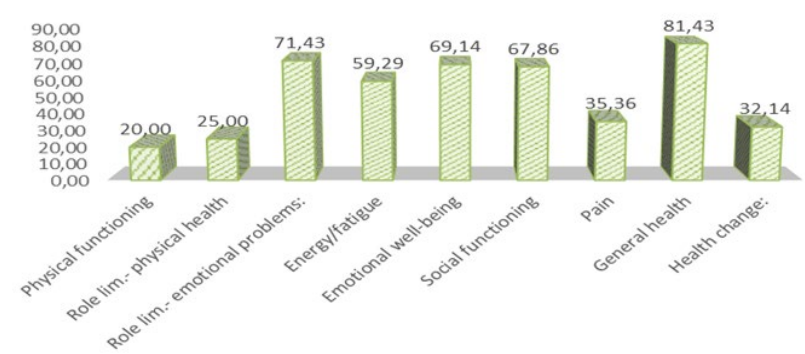

Fig 8. MOS SF-36 in alcoholic patient results If we make a comparison of the results of the SF36 MOS test in non-alcoholic patients with alcoholic patients, we notice how patients with addictions perceive more diminished: their physical functioning, limiting their physical health, their emotional well-being, their social functioning, pain and changes in their health; and patients with ethanolic dependence perceive more pronounced emotional problems, fatigue and their general health state.

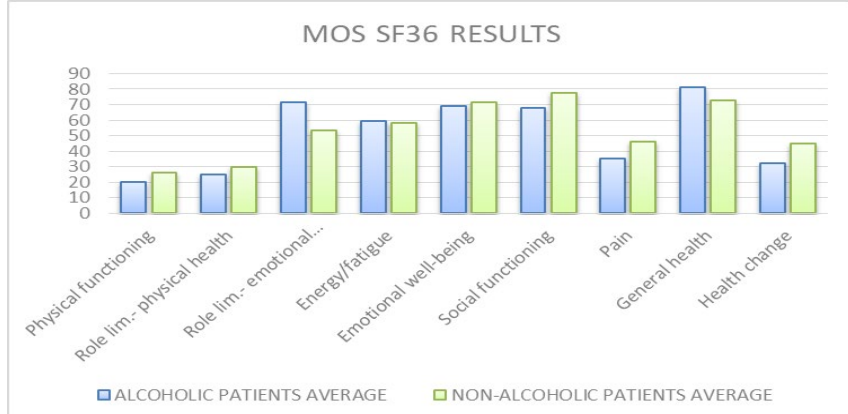

FIG 9. Common results of the MOS SF-36 test in patients with and without addictions
Then we calculated the averages of the DASS- 21 scale in ethanol consuming patients and we obtained the following values: 2.71 (for the depression score), 4.14 (for the anxiety score) and 5.71 (for the stress score).

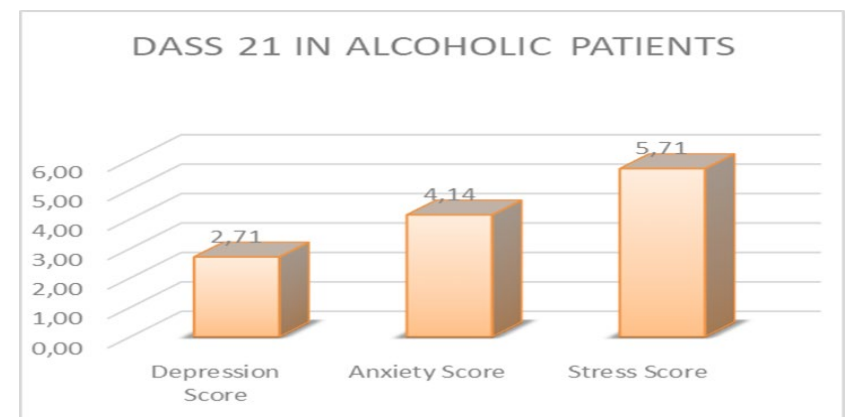

Fig10. DASS-21 results in alcoholic patients Similarly, we obtained averages of DASS-21 test results in non-alcoholic patients: 5.2 (for the depression score), 6.6 (for the anxiety score) and 5.5 (for the stress score).

\section{DASS-21 IN NON-ALCOHOLIC PATIENTS}

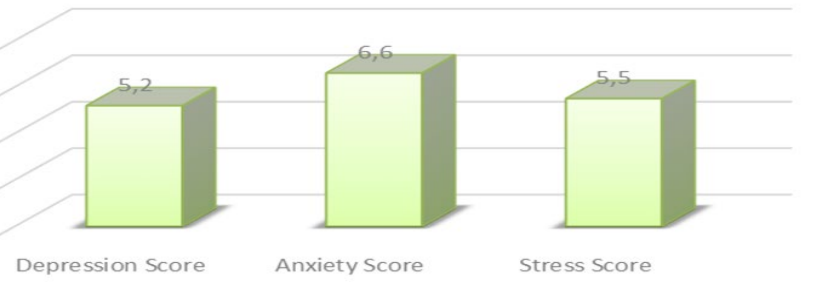

Fig 11. DASS-21 results in non-alcoholic patients Therefore, the comparative results of the DASS-21 test showed that non-ethanolic patients are more depressed and anxious, and alcohol users are more stressed in the acute and subacute stage after a spinal cord injury.

\section{DASS-21 RESULTS}

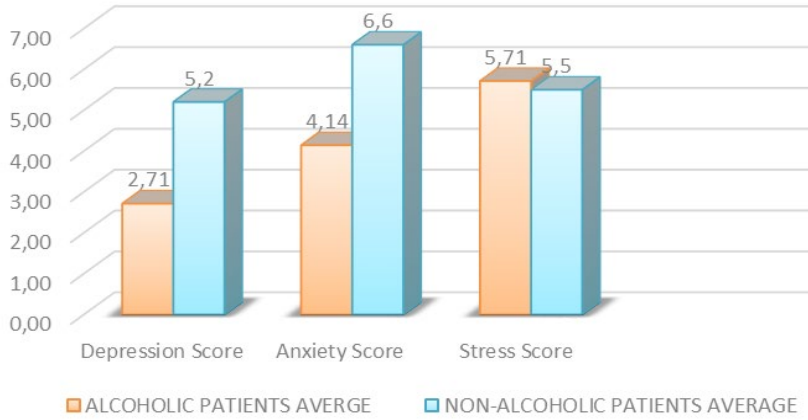

Fig 12. Results of DASS-21 averges in alcoholic versus non-ethanolic patients

\section{Conclusion}

Substance abuse (especially ethanol) increases the risk of spinal cord injury and is a serious public health problem. And substance abuse (especially ethanol) is evidence of depressive status. 
We studied a group of 17 patients consisting of 6 women $(35 \%)$ and $11(65 \%)$ men hospitalized after acute spinal cord injury, of which 7 men were abusively consuming ethanol.

We noticed how patients with addictions perceive more diminished: their physical functioning, their physical health limiting, their emotional well-being, their social functioning, pain and changes in their health; and patients with ethanolic dependence perceive more pronounced emotional problems, fatigue and their general health state.

Also, non-ethanolic patients are more depressed and anxious, while alcohol users are more stressed in the acute and subacute stage after a spinal cord injury.

\section{References}

1. Problematic secondary health conditions among adults with spinal cord injury and its impact on social participation and daily life. Piatt JA, Nagata S, Zahl M, Li J, Rosenbluth JP. Nov 2016, J Spinal Cord Med, Vol. 39(6), pp. 693-698.

2. Systemic Complications of Spinal Cord Injury. Sweis R, Biller J. Feb 2017 , Curr Neurol Neurosci Rep, Vol. $17(2)$, p. 8.

3. Respiratory problems and management in people with spinal cord injury. Berlowitz DJ, Wadsworth B, Ross J. Dec 2016, Breathe (Sheff), Vol. 12(4), pp. 328-340.

4. Epidemiology of Traumatic Spinal Cord Injury Among Persons Older Than 21 Years: A Population-Based Study in South Carolina, 1998-2012.2015 Fall;Epub 2015. Selassie A, Cao Y, Saunders LL. 2015, Top Spinal Cord Inj Rehabil, Vol. 21(4), pp. 333-44.

5. Change in the profile of traumatic spinal cord injury over 15 years in Spain. Bárbara-Bataller E, Méndez-Suárez JL, Alemán-Sánchez C, Sánchez-Enríquez J, Sosa-Henríquez M. Apr 5, 2018, Scand J Trauma Resusc Emerg Med, Vol. 26(1):27.

6. Preinjury alcohol and drug use among persons with spinal cord injury: implications for rehabilitation. Stroud MW, Bombardier CH, Dyer JR, Rimmele CT, Esselman PC. 2011, J Spinal Cord Med, Vol. 34(5), pp. 461-72.

7. Early versus delayed decompression for traumatic cervical spinal cord injury: results of the Surgical Timing in Acute Spinal Cord Injury Study (STASCIS). Fehlings MG, Vaccaro A, Wilson JR, Singh A, W Cadotte D, Harrop JS, Aarabi B, Shaffrey C, Dvorak M, Fisher C, Arnold P, Massicotte EM, Lewis S, Rampersaud R. 2012, PLoS One, Vol. 7(2).

8. A review of the Alcohol Use Disorders Identification Test (AUDIT), AUDIT-C, and USAUDIT for screening in the United States: Past issues and future directions. HigginsBiddle JC, Babor TF. 2018, Am J Drug Alcohol Abuse, Vol. 44(6), pp. 578-586.

9. Alcohol use, abuse and dependence among elderly in outpatient treatment through the application of AUDIT. Garcia PCO, Bassitt DP, Pinto FCG. Mar 2020 , Rev
Assoc Med Bras (1992), Vol. 66(3), pp. 307-313.

10. Alcohol and Drug Use in European University Health Science Students: Relationship with Self-Care Ability.; Colomer-Pérez N, Chover-Sierra E, Navarro-Martínez R, Andriusevičiené V, Vlachou E, Cauli O. Dec 11, 2019 , Int J Environ Res Public Health., Vol. 16(24):, p. 5042.

11. Alcohol abuse: prevalence and detection in a general hospital. Hearne R, Connolly A, Sheehan J. 2002, J R Soc Med., Vol. 95(2), pp. 84-87.

12. Alcohol and drug use disorders in patients with cancer and caregivers: effects on caregiver burden. Webber K, Davies AN, Leach C, Bradley A. Jun 2020 , BMJ Support Palliat Care, Vol. 10(2), pp. 242-247.

13. Validity of brief alcohol screening tests among adolescents: a comparison of the AUDIT, POSIT, CAGE, and CRAFFT. Knight JR, Sherritt L, Harris SK, Gates EC, Chang G. Jan 2003, Alcohol Clin Exp Res, Vol. 27(1), pp. 67-73.

14. Subdiagnostic alcohol use by depressed men and women seeking outpatient psychiatric services: consumption patterns and motivation to reduce drinking. Satre DD, Chi FW, Eisendrath S, Weisner C. Apr 2011, Alcohol Clin Exp Res., Vol. 35(4), pp. 695-702.

15. Alcohol interventions in a trauma center as a means of reducing the risk of injury recurrence. Gentilello LM, Rivara FP, Donovan DM, et al. 473-483, 1999, Ann Surg, Vol. 230(4).

16. Screening for depression and anxiety in spinal cord injury with DASS-21. Mitchell MC, Burns NR, Dorstyn DS. Aug 2008 , Spinal Cord, Vol. 46(8), pp. 547-51.

17. Prevalence and psychometric screening for the detection of major depressive disorder and post-traumatic stress disorder in adults injured in a motor vehicle crash who are engaged in compensation. Guest R, Tran Y, Gopinath B, Cameron ID, Craig A. Feb. 2018, BMC psychology, Vols. 6,1 4.

18. The mediating role of psychological symptoms on falls risk among older adults with osteoarthritis. Mat S, $\mathrm{Ng} \mathrm{CT}$, Fadzil F, Rozalli FI, Tan MP. Nov 28, 2017 , Clin Interv Aging, Vol. 12, pp. 2025-2032.

19. Health-related Quality of Life Evaluated by MOS SF-36 in the Elderly Patients 1 Month before ICU Admission and 3 Months after ICU Discharge. Zeggwagh Z, Abidi K, Kettani MN, Iraqi A, Dendane T, Zeggwagh AA. Jul 2020, Indian J Crit Care Med, Vol. 24(7), pp. 531-538.

20. Effects of Online Home Nursing Care Model Application on Patients with Traumatic Spinal Cord Injury. Li QP, Li J, Pan HY. Apr 23, 2021, Risk Manag Healthc Policy, Vol. 14, pp. 1703-1709.

21. Hot Water Extract of Curcuma longa L. Improves Serum Inflammatory Markers and General Health in Subjects with Overweight or Prehypertension/Mild Hypertension: A Randomized, Double-Blind, Placebo-Controlled Trial. Uchio R, Muroyama K, Okuda-Hanafusa C, Kawasaki K, Yamamoto Y, Murosaki S. Aug 7, 2019 , Nutrients, Vol. 11(8), p. 1822. 